Supporting Information

\title{
An mRNA-activated Multifunctional DNAzyme Nanotweezer for Intracellular mRNA Sensing and Gene Therapy
}

Manman He, Mengyun He, Cunpeng Nie, Jintao Yi, Juan Zhang, Tingting Chen, Xia

$$
\text { Chu* }
$$

State Key Laboratory of Chemo/Bio-Sensing and Chemometrics, College of Chemistry and Chemical Engineering, Hunan University, Changsha 410082, P. R. China

E-mail: xiachu@hnu.edu.cn

Phone/Fax: +86-731-88821916. 


\section{Materials and reagents}

All DNA and mRNA sequences were Purified by HPLC and provided by Sangon Biotech Co. Ltd. (Shanghai, China). Hoechst 33342, tamoxifen and $\beta$-estradiol were obtained from Sigma-Aldrich Co., Ltd. (St. Louis, MO, USA). CCK-8 reagent, LysoTracker@Red DNA-99 and Dead Cell Apoptosis Kit were obtained from Thermo Fisher Scientific Inc (MA, USA). BCA protein assay kit, RIPA Lysis Buffer, Nuclear and Cytoplasmic Protein Extraction Kit and phenylmethanesulfonyl fluoride (PMSF) were supplied by Beyotime Biotechnology. Anti-survivin antibody and anti- $\beta$-actin antibody were obtained from Santa Cruz Biotechnology. All solutions were prepared with ultrapure water obtained from Millipore Milli-Q water purification system (Billerica, MA, USA).

\section{Apparatus}

Fluorescence spectra was obtained from the Fluorescence Spectrometer FS5 (Hitachi, Japan) with emission and excitation slits of $5.0 \mathrm{~nm}$. Atomic force microscopy (AFM) imaging of DZNT was performed on a Multimode 8 (Bruker, USA). Dynamic light scattering (DLS) of DZNT was carried out on a Malvern Zetasizer Nano ZS90 (Malvern, England). Flow cytometric analysis was carried on CytoFLEX (Beckman Coulter Commercial Enterprise (China) Co., Ltd.). ELx800 ${ }^{\mathrm{TM}}$ microplate reader (BioTek, USA) was used for assessing Cell viability. Confocal laser scanning microscopy (CLSM, Nikon A1R MP, Japan) was used for all cell microscopy images of $60 \times$ oil dipping objective.

\section{Agarose gel electrophoresis}

In the agarose gel electrophoresis test, the samples $(1.0 \mu \mathrm{M})$ were mixed with $6 \times$ loading buffer and measured with $2 \%$ agarose gel. At $110 \mathrm{~V}$ constant voltage, the gel electrophoresis was carried on $0.5 \times$ Tris-Borate-EDTA buffer for $90 \mathrm{~min}$ at ice temperature. The gel was analyzed by a Tanon 4200SF gel imaging system.

\section{Serum stability assay}

To estimate the stability of the DZNT, $1 \mu \mathrm{M}$ DZNT was dispersed in $10 \mu \mathrm{L}$ DMEM medium containing $10 \%$ FBS and incubated at $37{ }^{\circ} \mathrm{C}$ for different times. Then, $1 \mu \mathrm{L}$ $800 \mathrm{U} / \mathrm{mL}$ proteinase $\mathrm{K}$ was added at $37{ }^{\circ} \mathrm{C}$ and incubated for $4 \mathrm{~h}$ for protein 
degradation to reduce the binging of DNA and proteins. Finally, $2 \mu \mathrm{L} 6 \times$ loading buffers was added to each sample for electrophoresis experiments. The gel was analyzed by the Tanon 4200SF gel imaging system.

\section{Atomic force microscopy (AFM)}

The DZNT were characterized by AFM (Bruker multimode 8). $50 \mu \mathrm{L} 200 \mathrm{nM}$ sample was deposited on the newly cleaved mica surface (Ted Pella, Inc., USA) and absorbed for $20 \mathrm{~min}$ for AFM imaging. Then the sample is lightly rinsed three times with deionized water and dried in the air. AFM images were collected in air under scanning Asyst mode. NanoScope analysis software was used to flatten the image background.

\section{The preparation of samples for the ICP-MS experiment}

After cells reached $\sim 70 \%$ confluence, the cell media was replaced with $1.0 \mathrm{~mL}$ fresh cell culture medium containing $5 \mathrm{mM} \mathrm{MnCl}_{2}$. Then cells were treated with $\mathrm{MnCl}_{2}$ for $6 \mathrm{~h}$ to allow sufficient cellular uptake. To determine the intracellular concentration of $\mathrm{Mn}^{2+}$, cells were thoroughly washed with $1 \times \mathrm{PBS}$ for six times and incubated with fresh medium for 20 min to further reduce membrane-bound $\mathrm{Mn}^{2+}$. Then cells were detached using $0.05 \%$ trypsin and collected by centrifugation. The total number of cells was counted using a hemocytometer. Next, added $50 \mu \mathrm{L}$ cell lysate to fully cleave the cells. The concentration of $\mathrm{Mn}^{2+}$ was measured by using ICP-MS.

\section{Cytotoxicity assays of DZNT}

The cytotoxicity of DZNT in vitro was determined by Cell Counting Kit-8 method. HepG2 and L02 cells $\left(6 \times 10^{3}\right.$ cells $\left./ \mathrm{mL}\right)$ were placed in 96-well plates and cultured in fresh DMEM medium for $24 \mathrm{~h}$ at $37^{\circ} \mathrm{C}$. Then, cells were incubated with DZNT (100, 200 , and $500 \mathrm{nM}$ ) for different time, respectively. After that, cells were washed two times with $1 \times$ PBS and cultivated in a fresh DMEM medium containing $10 \%$ CCK-8 for another $2 \mathrm{~h}$ at $37^{\circ} \mathrm{C}$. Finally, the cell viability was detected at $450 \mathrm{~nm}$ absorbance with an ELx800 ${ }^{\mathrm{TM}}$ microplate reader.

\section{Quantitative reverse transcriptase-PCR analysis}

For TK1 mRNA expression, HepG2 cells $\left(1.0 \mathrm{~mL}, 1 \times 10^{7}\right.$ cells $)$ were cultivated 
with tamoxifen $\left(10^{-5} \mathrm{M}\right)$ and $\beta$-estradiol $\left(10^{-7} \mathrm{M}\right)$ at $37^{\circ} \mathrm{C}$ for $24 \mathrm{~h}$ before total RNAs was extracted by utilizing Uniq-10 column Trizol total RNA extraction kit. The cDNA samples were prepared by the Maxima Reverse Transcriptase kit. The cDNA samples were diluted 10 times as a template for computer detection. The TK1 mRNA expression levels were tested with a SybrGreen qPCR Master Mix on a Stepone Plus qPCR instrument. The detailed steps were as follows: A $20 \mu \mathrm{L}$ of reaction solution were kept at $95{ }^{\circ} \mathrm{C}$ for $3 \mathrm{~min}$ followed by 45 cycles at $95^{\circ} \mathrm{C}$ for $5 \mathrm{~s}$ and at $60{ }^{\circ} \mathrm{C} 30 \mathrm{~s}$. $\beta$-actin RNA was used as endogenous control to quantify TK1 mRNA relative expression level. The $2^{-(\Delta \Delta \mathrm{Ct})}$ method was utilized to calculate TK1 mRNA relative expression level. Primers for qPCR were following:

TK1 forward primer, 5'-CTCCTACCCACTGGTATGCTTA-3';

TK1 reverse primer, 5'-CAGGGAGAACAGAAACTCAGCA-3';

$\beta$-actin forward primer, 5'-TAGTTGCGTTACACCCTTTCTTG-3';

$\beta$-actin reverse primer, 5'-TCACCTTCACCGTTCCAGTTT-3'.

For survivin mRNA relative expression level was also measured by RT-PCR assay. Total cellular RNA was extracted from these groups of HepG2 cells: $200 \mathrm{nM}$ ssDNAzyme@Mn²+,200 nM control DZNT@Mn²+,200nM control target DZNT@ $\mathrm{Mn}^{2+}, 200$ nM DZNT and 200 nM DZNT@Mn². The detailed steps were the same as the qPCR analysis of TK1 mRNA expression. The expression level of Survivin mRNA also was evaluated by normalizing the expression of $\beta$-actin using $2^{-(\Delta \Delta C t)}$ method. The primers for $\mathrm{qPCR}$ were used as follow:

Survivin forward primer, 5'-GCCATTAACCGCCAGATTT-3';

H-survivin reverse primer, 5'-CCTCTGCGACAGCTTATAATGG-3';

$\beta$-actin forward primer, 5'-TAGTTGCGTTACACCCTTTCTTG-3';

$\beta$-actin reverse primer, 5'-TCACCTTCACCGTTCCAGTTT-3'.

\section{The extraction of total proteins}

Nuclear and Cytoplasmic Protein Extraction Kit was used to extract total protein. Briefly, the cells were washed two times with $1 \times$ PBS after pretreatment at $37^{\circ} \mathrm{C}$ for 48 h with 200 nM ssDNAzyme@Mn²+, 200 nM control DZNT@Mn²+, 200 nM control target DZNT@Mn ${ }^{2+}, 200$ nM DZNT and 200 nM DZNT@Mn². Then, the 
cells were cultivated in $80 \mu \mathrm{L}$ RIPA lysis buffer with $1 \%$ proteinase inhibitor cocktail on ice for $30 \mathrm{~min}$. Total protein was centrifuged at $12000 \mathrm{rpm}$ for $15 \mathrm{~min}$. The supernatant was collected and the total Protein was calibrated with BCA Protein Assay Kits. The supernatant was stored at $-80{ }^{\circ} \mathrm{C}$ for further investigate survivin protein expression level.

\section{Western blot analysis}

Survivin protein expression was discussed by western blot analysis. Briefly, the total proteins with an equal amount from different samples were loaded on $10 \%$ SDS-PAGE for $40 \mathrm{~min}$ at $80 \mathrm{mV}$ and $90 \mathrm{~min}$ at $120 \mathrm{mV}$. Next, the total protein was transferred to polyvinylidene fluoride (PVDF) membrane for $2 \mathrm{~h}$ at $230 \mathrm{~mA}$. After sealing with $5 \%$ skim milk, PVDF membrane was incubated with survivin primary antibody (1:250) at $4{ }^{\circ} \mathrm{C}$ overnight, and then incubated with HRP-conjugated secondary antibody (1:5000) for $2 \mathrm{~h}$ before imaging. $\beta$-actin was chosen as endogenous control.

\section{The construction of multicellular tumor spheroids}

The construction of multicellular tumor spheres was based on existing protocols with minor modifications. ${ }^{1}$ The specific steps were as follows: firstly, $1.0 \%$ agarose solution was prepared in Milli-Q water and heated to boiling in microwave oven. Then, quickly added to the 96-well plate, each well coated with $60 \mu \mathrm{L}$ agarose solution, and irradiated with UV for $15 \mathrm{~min}$ for sterilization. Finally, $100 \mu \mathrm{L}$ of DMEM solution containing 500 cells were added to a 96-well plate coated with agarose. The medium was changed every 3 days, and multicellular tumor globules were formed for 3-7 days. 
Table S1. Oligonucleotides used in this work.

\begin{tabular}{|c|c|}
\hline Name & Sequence $\left(5^{\prime}-3{ }^{\prime}\right)$ \\
\hline Strand 1 & $\begin{array}{l}\text { TCGACCGAGCGTGAATTAGTGATCCGGAACTCGCGCAATGAAC } \\
\text { C }\end{array}$ \\
\hline Strand 2 & $\begin{array}{l}\text { TCAGCTGGCCTATCTAAGACTGAACTCGCACCGCCGGCATAAG } \\
\text { CTATGCGCTCTGCCGC }\end{array}$ \\
\hline Strand 3 & $\begin{array}{l}\text { TTAGGAGATGGCACGTTAATGAATAGTCTCCACTTGCATCCGAG } \\
\text { A TCC GAA CTG CTG CC }\end{array}$ \\
\hline Strand 4 & CGAGAGAAGGCTTGCCAGGTTACGTTCGTACATCGTCTGAGTT \\
\hline Strand 5 & GGCAGCAGTTCAGGCCAGCTGA \\
\hline Strand 6 & $\begin{array}{l}\text { GGTTCATTGCGGAGTTCAGTCTTAGATGGATCTCGGATGCAAGG } \\
\text { ССТTCTCTCG }\end{array}$ \\
\hline Strand 7 & GGTGCCGAGTTCCGGATCACTAATTCCATAGCTTATGCCGGC \\
\hline Strand 8 & $\begin{array}{l}\text { TCGGCCAGGCTAGCAT(Cy3)CACCAGGCACTTGttttGCGGCAGA } \\
\text { GCGACGCTCGGTCG }\end{array}$ \\
\hline Strand 9 & $\begin{array}{l}\text { AACTCAGACGACCATCTCCTAAtttttGTGTCTTTGGCATACTT(Cy5) } \\
\text { GTACAACGACCGCTCCG }\end{array}$ \\
\hline Strand 10 & ACTATTCATTAACGTGTGTACGAACGTAACCTGGCAATGGAG \\
\hline ssDNAzyme & TCGGCCAGGCTAGCTACAACGACCGCTCC \\
\hline Control-DNAzyme & $\begin{array}{l}\text { AACTCAGACGACCATCTCCTAAtttttGTGTCTTTGGCATACTTGTA } \\
\text { CAACGACTGCTCCG }\end{array}$ \\
\hline Control-target & AACTCAGACGACCATCTCCTAAttttGTGTTTTTGGCATTCTTGTA \\
\hline DNAzyme & CAACGACCGCTCCG \\
\hline Substrate & Dabcyl-CGGAGCGGrArUGGCCGA-FAM \\
\hline TK1 mRNA & CAAGUGCCUGGUGAUCAAGUAUGCCAAAGACAC \\
\hline Target mismatch1 & CAAGUGCCUGAUGAUCAAGUAUGCCAAAGACAC \\
\hline Target mismatch2 & CAAGUGCCUGAUGAUCAAAUAUGCCAAAGACAC \\
\hline Target mismatch3 & CAAGUGCAUGGUGAUAAAGUAUGCAAAAGACAC \\
\hline Survivin mRNA & UCUCAAGGACCACCGCAUCUCUAC \\
\hline$\beta$-actin mRNA & UCUCGCGCCCUCCACCAUGAAGAUC \\
\hline MnSOD mRNA & AAUCAACUGGGAGAAUGUAACUG \\
\hline
\end{tabular}

Note: The red denotes mismatched base. The Control-DNAzyme contains a mismatched base $\mathrm{T}$ in the splitting DNAzyme segment, which would result in the failure in the substrate cleavage. The Control-target DNAzyme contains two mismatched bases $\mathrm{T}$ in the hybridization segment with target mRNA, which would make DZNT unable to hybridize with target mRNA. 
Table S2. Intracellular $\mathrm{Mn}^{2+}$ concentration determined by inductively coupled plasma mass spectrometry (ICP-MS).

\begin{tabular}{cc}
\hline Sample & $\mathrm{Mn}^{2+}(\mathrm{pg} /$ cell $)$ \\
\hline $\mathrm{Mn}^{2+}$ & 0.309 \\
\hline
\end{tabular}

To determine the intracellular concentration of $\mathrm{Mn}^{2+}$, cells were thoroughly washed with $1 \times$ PBS for six times and incubated with fresh medium for 20 min to further reduce membrane-bound $\mathrm{Mn}^{2+}$. Then cells were detached using $0.05 \%$ trypsin and collected by centrifugation. The total number of cells was counted using a hemocytometer. The concentration of $\mathrm{Mn}^{2+}$ was measured by using ICP-MS (NexION300x, USA). The intracellular concentrations of $\mathrm{Mn}^{2+}$ was determined to be $\sim 1.227 \mathrm{mM}$ (assuming 2,000 $\mu \mathrm{m}^{3}$ as the volume of a HepG2 cell), which was sufficient to aid the DNAzyme to cleave the substrate. 

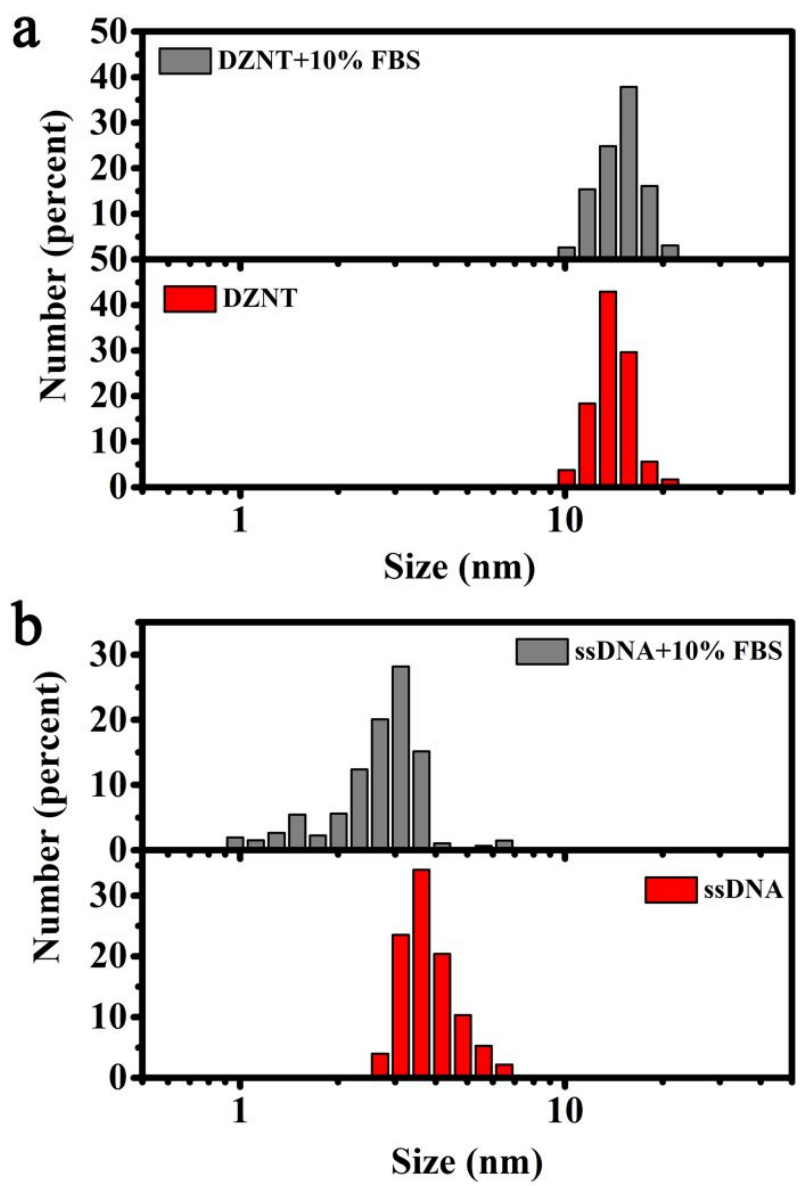

Figure S1. The stability of DZNT and ssDNA in 10\% FBS for $48 \mathrm{~h}$ was verified by DLS analysis. (a) DZNT and DZNT with $10 \%$ FBS. (b) ssDNA and ssDNA with $10 \%$ FBS. 

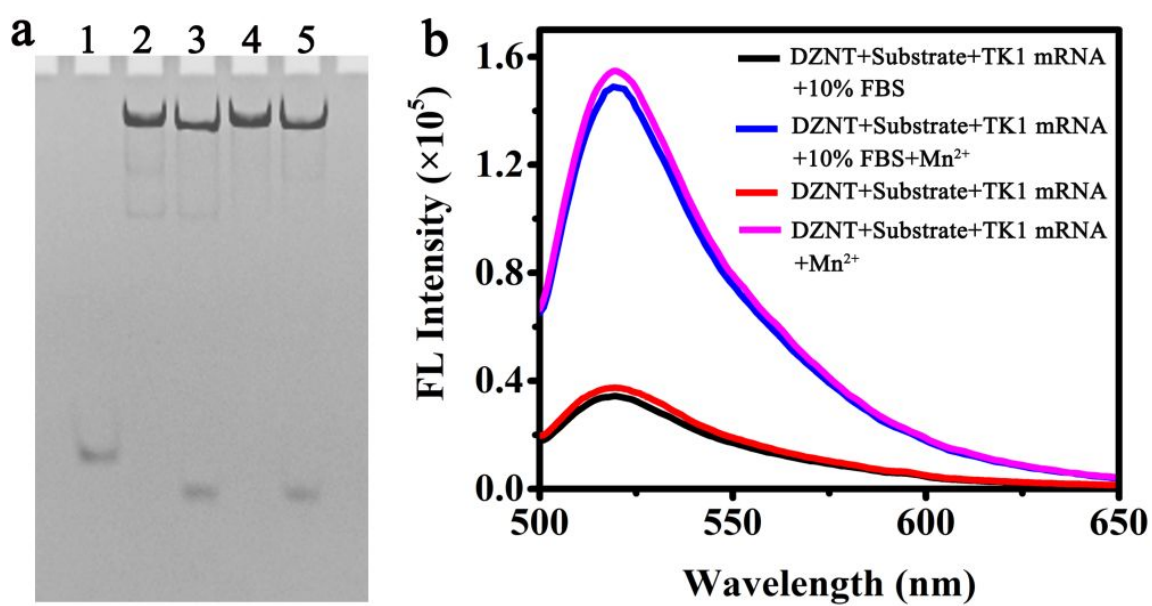

Figure S2. The stability of DZNT in 10\% FBS for 48 h. (a) Native PAGE (5\%) after incubation for $48 \mathrm{~h}$ of $2 \mu \mathrm{M}$ substrate (1); $2 \mu \mathrm{M}$ DZNT $+10 \%$ FBS $+2 \mu \mathrm{M}$ TK1 mRNA $+2 \mu \mathrm{M}$ substrate (2); $2 \mu \mathrm{M}$ DZNT $+10 \% \mathrm{FBS}+2 \mu \mathrm{M}$ TK1 mRNA $+2 \mu \mathrm{M}$ substrate $+1.4 \mathrm{mM} \mathrm{Mn}^{2+}(3) ; 2 \mu \mathrm{M}$ DZNT $+2 \mu \mathrm{M}$ TK1 mRNA + $2 \mu \mathrm{M}$ substrate (4); and $2 \mu \mathrm{M}$ DZNT $+2 \mu \mathrm{M}$ TK1 mRNA $+2 \mu \mathrm{M}$ substrate $+1.4 \mathrm{mM} \mathrm{Mn}^{2+}(5)$. (b) Fluorescence spectra of different solutions as indicated in the inset of Figure b. 


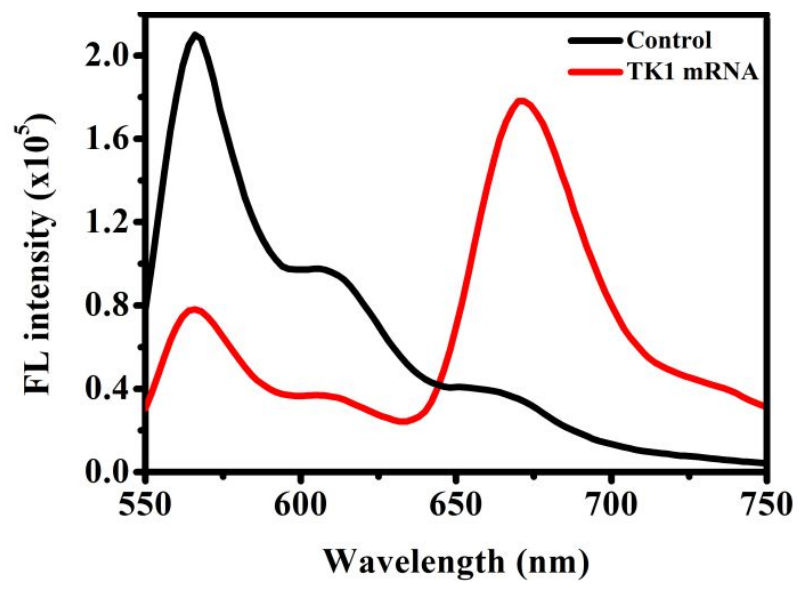

Figure S3. Fluorescence spectra of feasibility analysis of the DZNT responsive to target TK1 mRNA. 

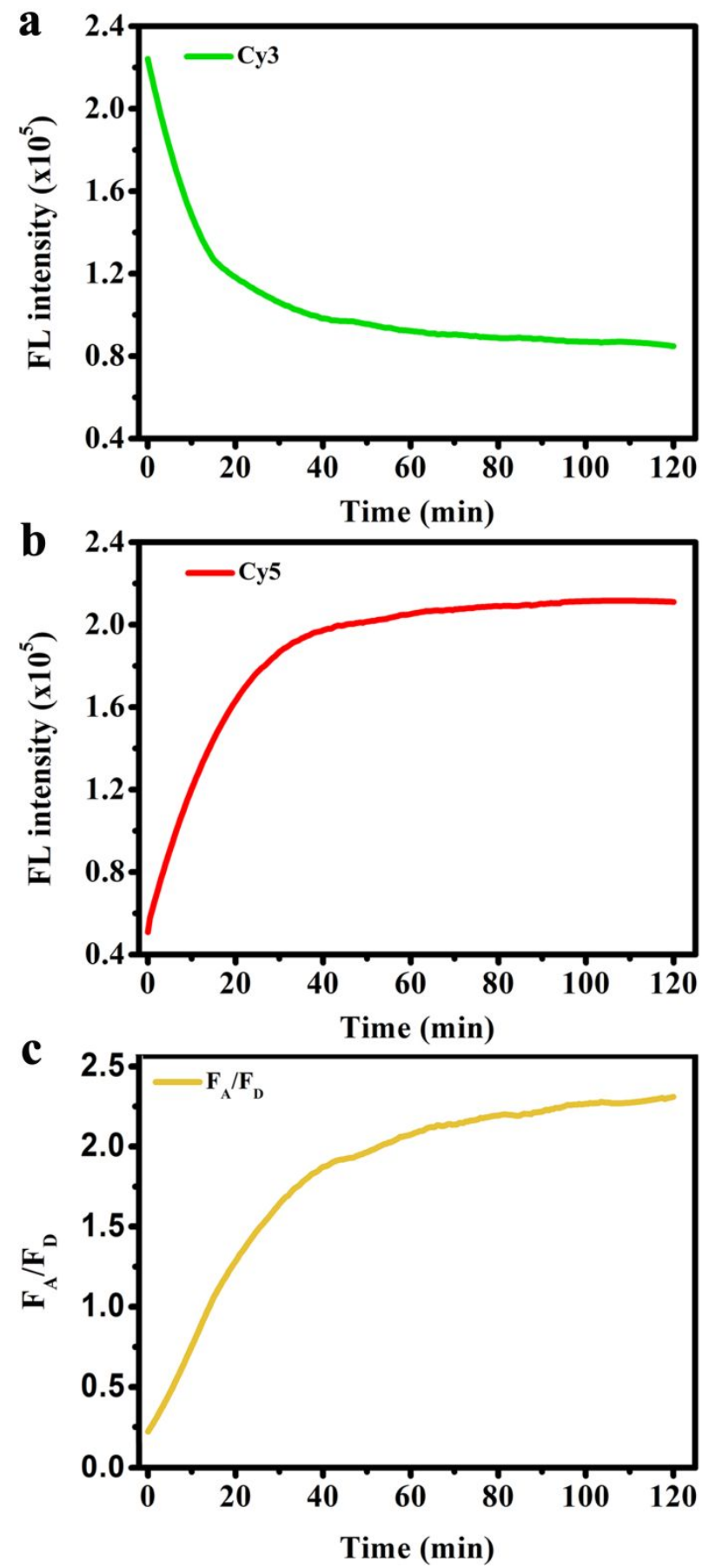

Figure S4. Kinetics curves of DZNT. The change of fluorescence emission intensity with time after adding target TK1 mRNA $(25 \mathrm{nM})$ to DZNT was recorded in real time. Variation of fluorescence intensity of $\mathrm{Cy} 3$ (a) and Cy5 (b). (c) The ratio changes of Cy5 to $\mathrm{Cy} 3\left(\mathrm{~F}_{\mathrm{A}} / \mathrm{F}_{\mathrm{D}}\right)$. 

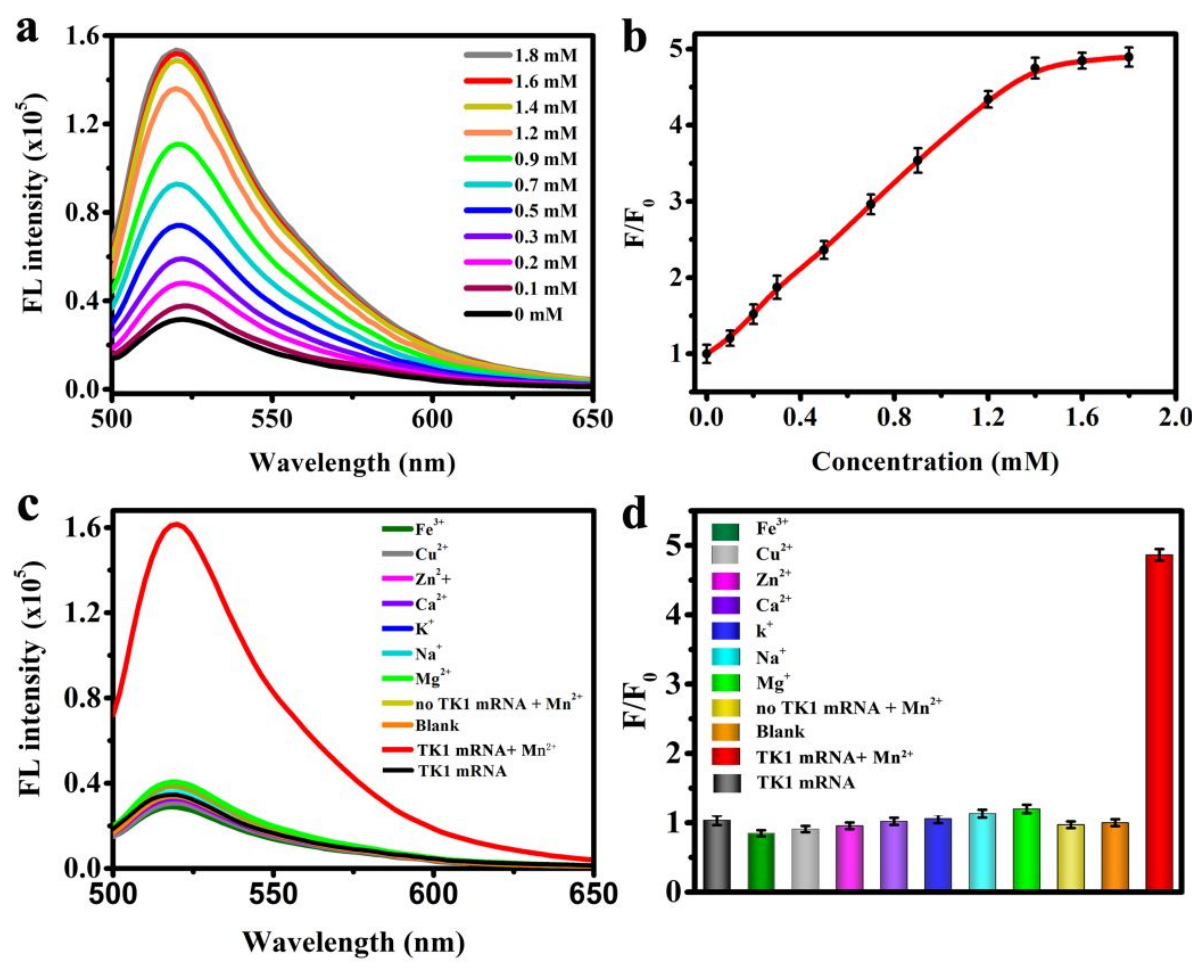

Figure S5. (a) The fluorescence spectral of DZNT cleavage substrate after incubation with varying concentrations of $\mathrm{Mn}^{2+}$. (b) Relationship between fluorescence intensity at $518 \mathrm{~nm}$ and the concentration of $\mathrm{Mn}^{2+}$ from 0 to $1.8 \mathrm{mM}$. (c) Specificity of DZNT cleavage substrate with $\mathrm{Mn}^{2+}(1.4 \mathrm{mM})$ over other metal ions. $\left(\mathrm{Na}^{+}\right.$and $\mathrm{K}^{+}, 100 \mathrm{mM}$; $\mathrm{Mg}^{2+}, \mathrm{Ca}^{2+}$ and $\mathrm{Zn}^{2+}, 2 \mathrm{mM} ; 20 \mu \mathrm{M}$ for all others). (d) Histogram of the specificity of DZNT to $\mathrm{Mn}^{2+}$. Each error bar was calculated from three parallel measurements. 


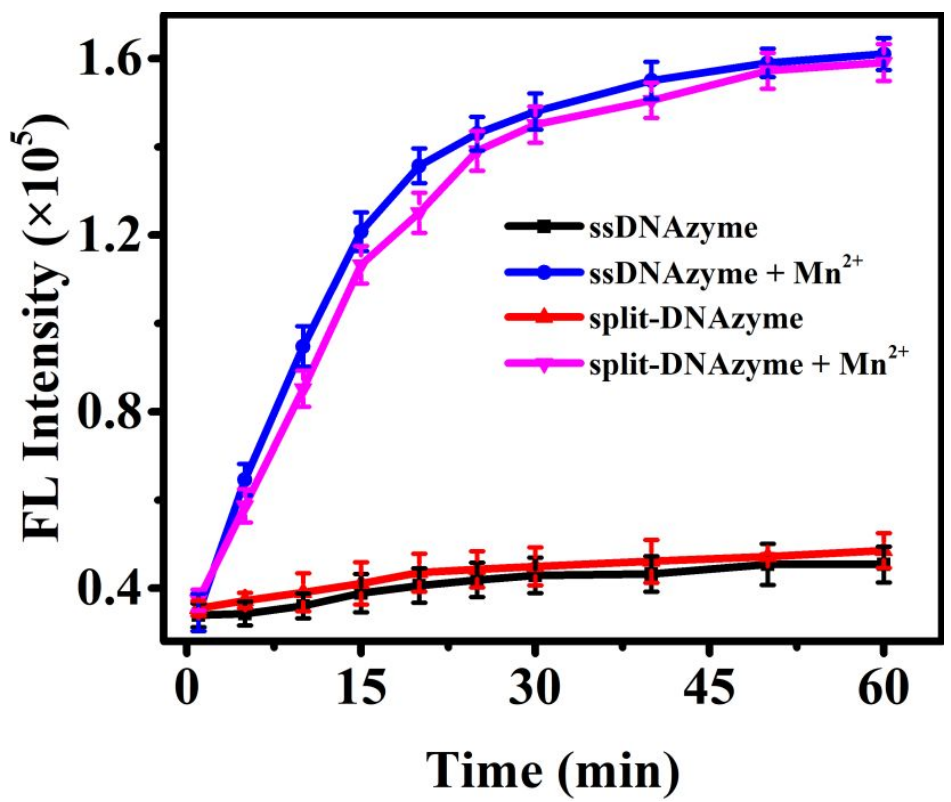

Figure S6. The comparision of the split-DNAzyme and ssDNAzyme catalytic activity 


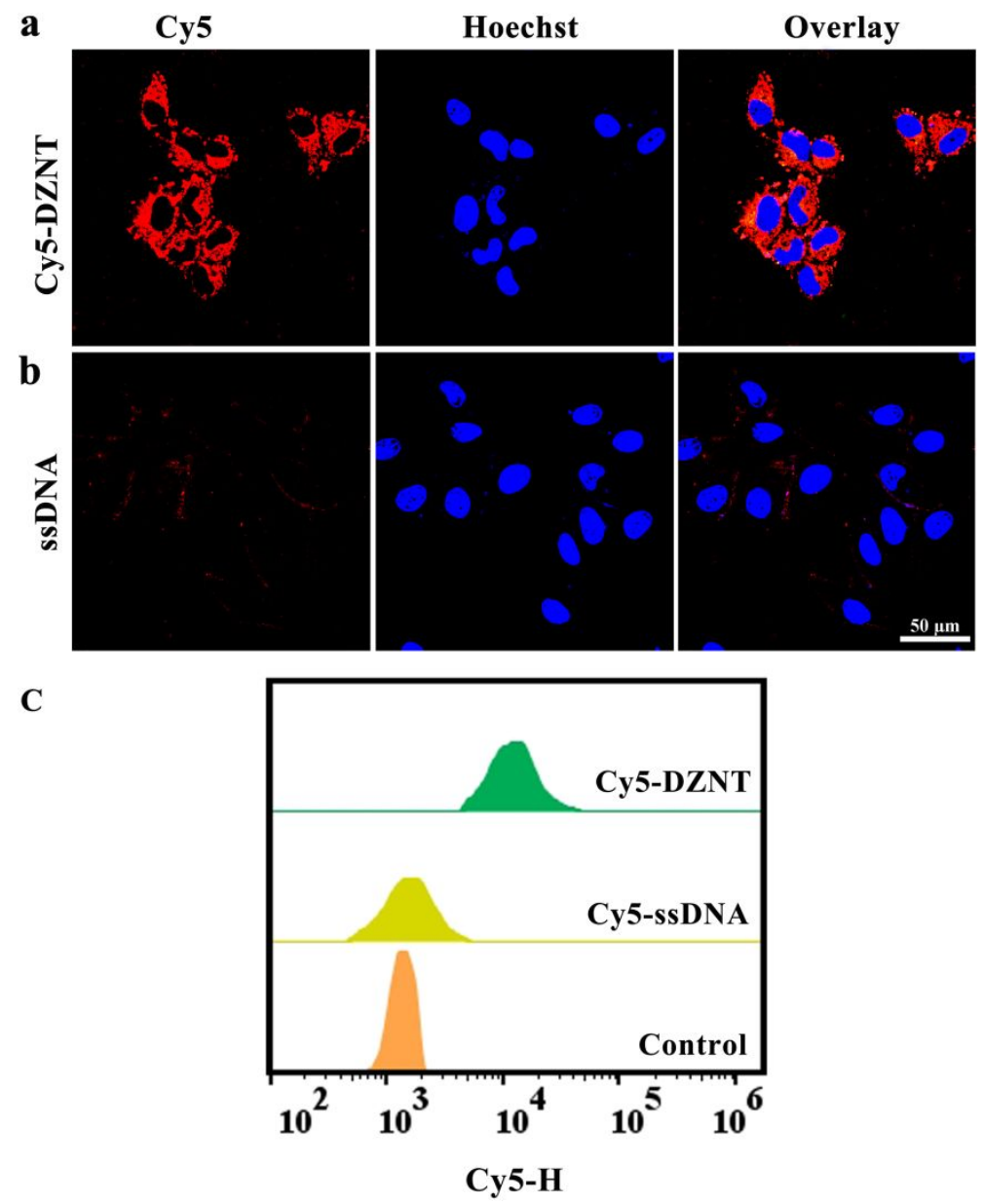

Figure S7. CLSM images of HepG2 cells incubated with Cy5-labeled DZNT (a) and Cy5-labeled ssDNA (b) at $37{ }^{\circ} \mathrm{C}$ for $5 \mathrm{~h}$, respectively. (c) Flow cytometry assay for cells incubation with Cy5-labeled ssDNA and DZNT. 


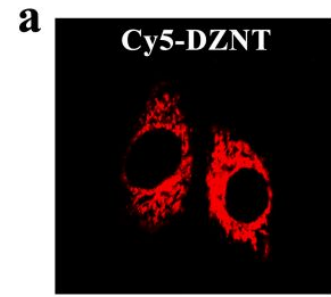

Hoechst

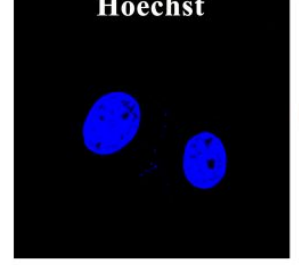

b

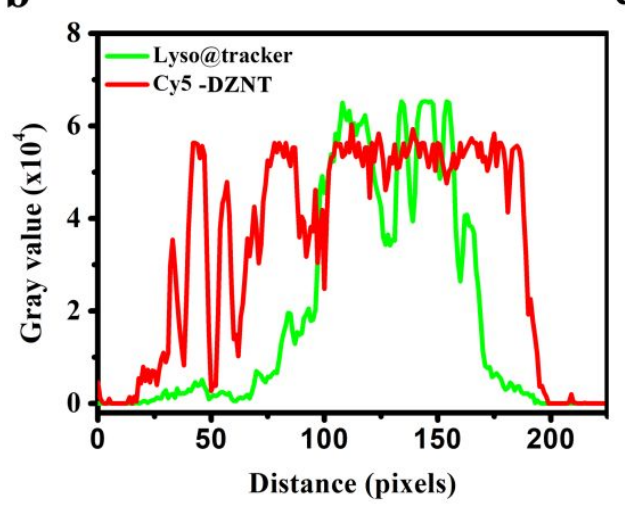

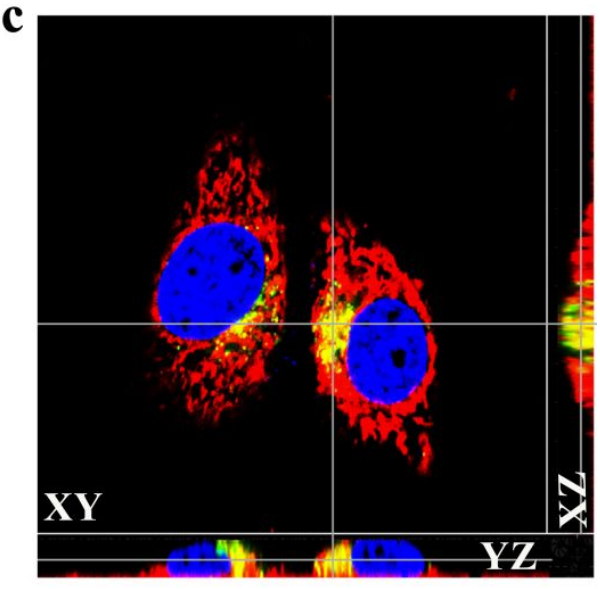

d $\circ$

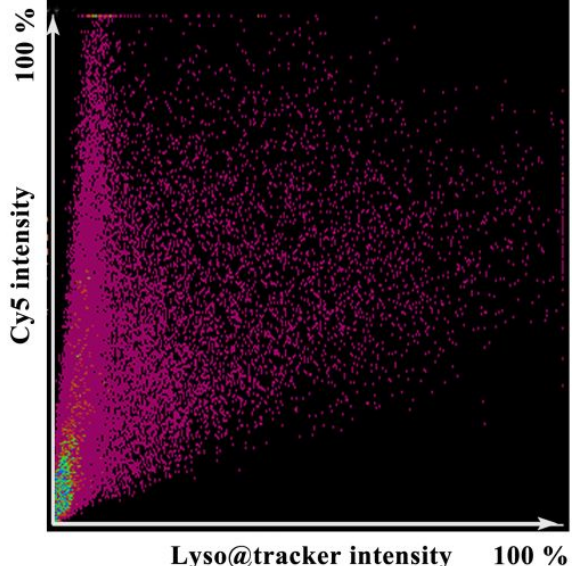

Figure S8. (a) Lysosomal escape of DZNT in HepG2 cells. (b) Fluorescence intensity distribution of the region of interest (white arrow) of the Lyso@tracker (green line) and the DZNT (red line). (c) Confocal z-stacks images with a cross-section in XZ, XY and YZ. HepG2 cells were cultivated with DZNT motified with Cy5 (Red), followed by staining with Hoechst (nucleus, blue), and 100 nM lyso@tracker (lysosomal, Green) for 10 min. (d) The colocalization coefficient of the DZNT (red channel) and the Lyso@tracker (green channel). 


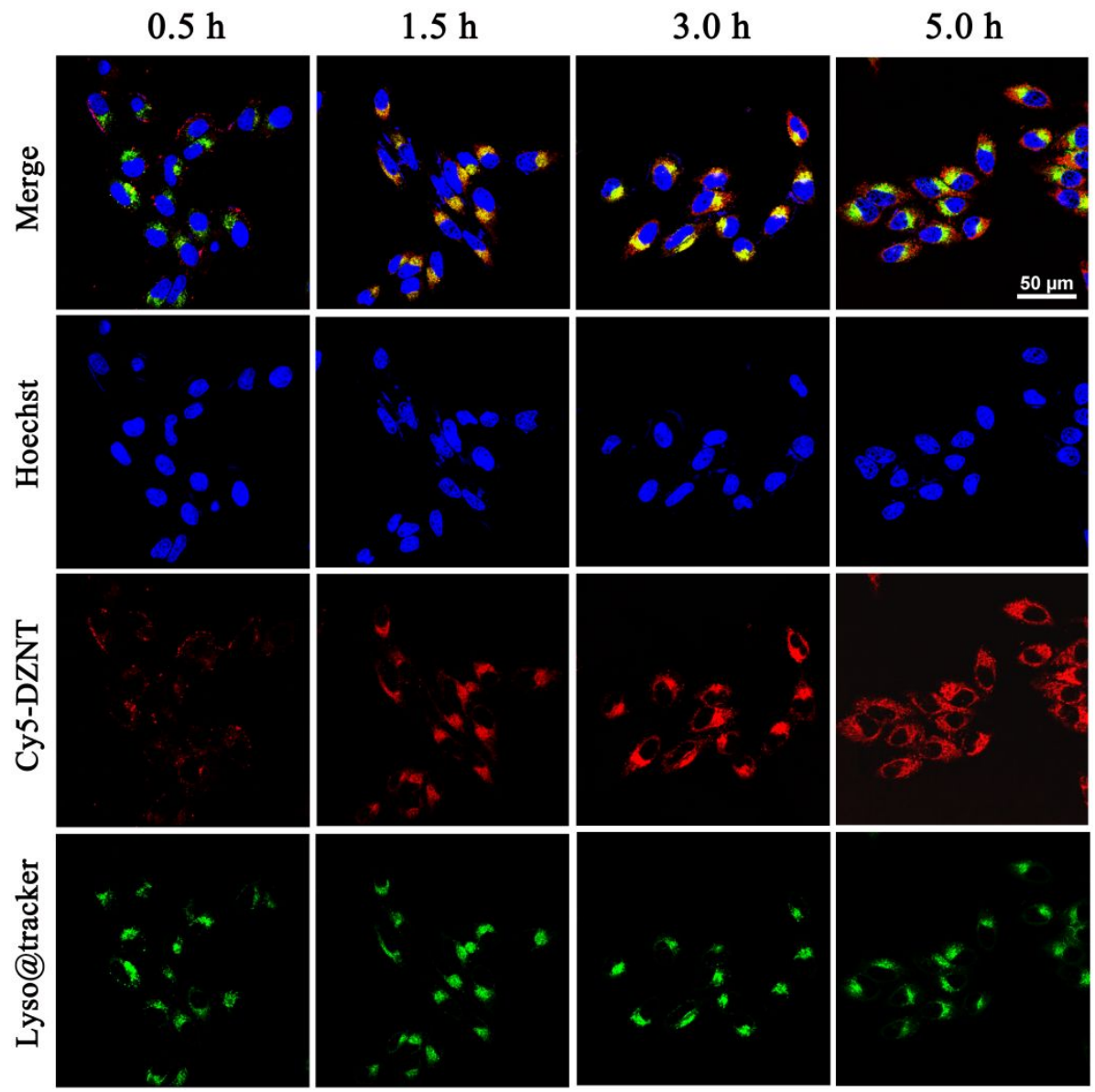

Figure S9. The process of DZNT escape from lysosome. CLSM corresponding to Cy5-DZNT (red) were incubated with HepG2 cells for $0.5 \mathrm{~h}, 1.5 \mathrm{~h}, 3.0 \mathrm{~h}$ and $5 \mathrm{~h}$, respectively. 


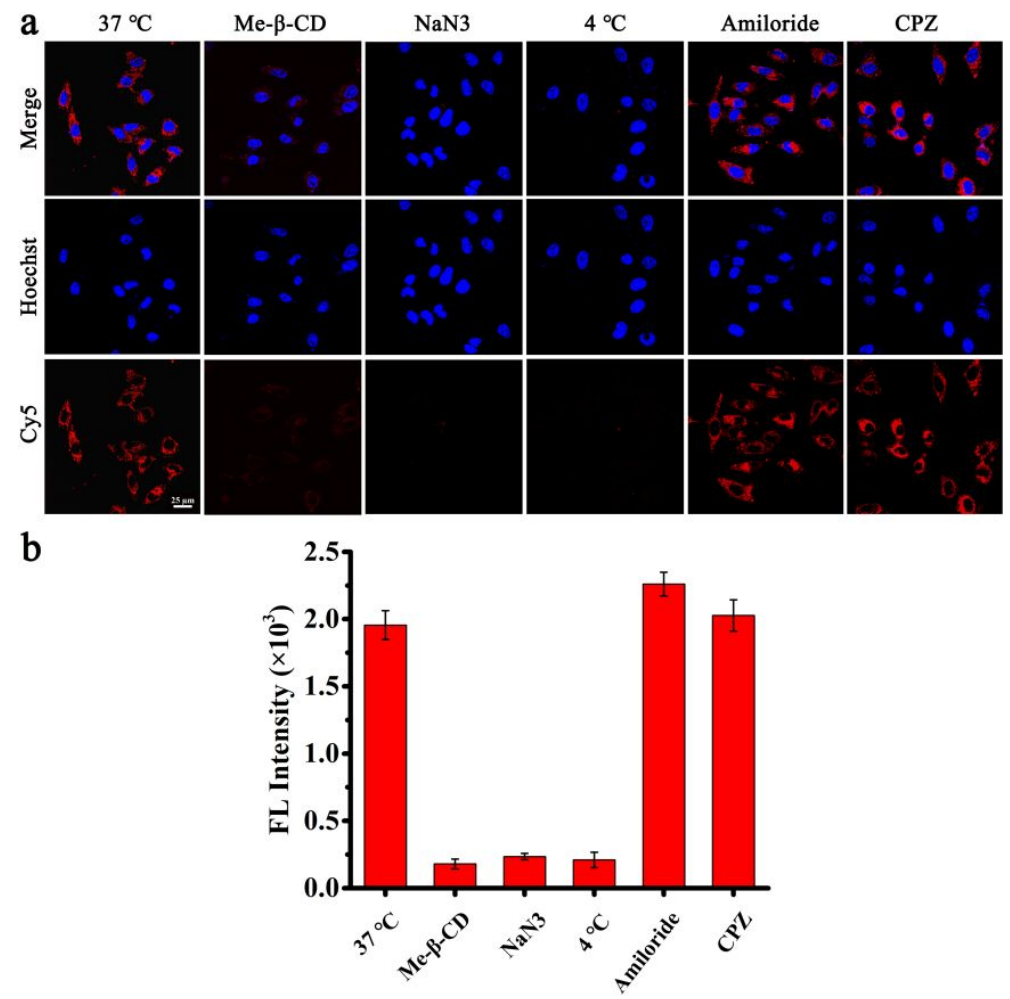

Figure S10. Endocytosis pathway study of DZNT. (a) CLSM images of HepG2 cells pretreated with different endocytosis inhibitor (Me- $\beta-\mathrm{CD}: 0.5 \mathrm{mM}, \mathrm{NaN}_{3}: 0.1 \%$, w/v, Amiloride: $2 \mathrm{mM}$ and CPZ: $20 \mu \mathrm{g} / \mathrm{mL}$ ) and then incubated with Cy5-DZNT for $5 \mathrm{~h}$. (b) The corresponding histogram of the fluorescence intensity of the above situation. 


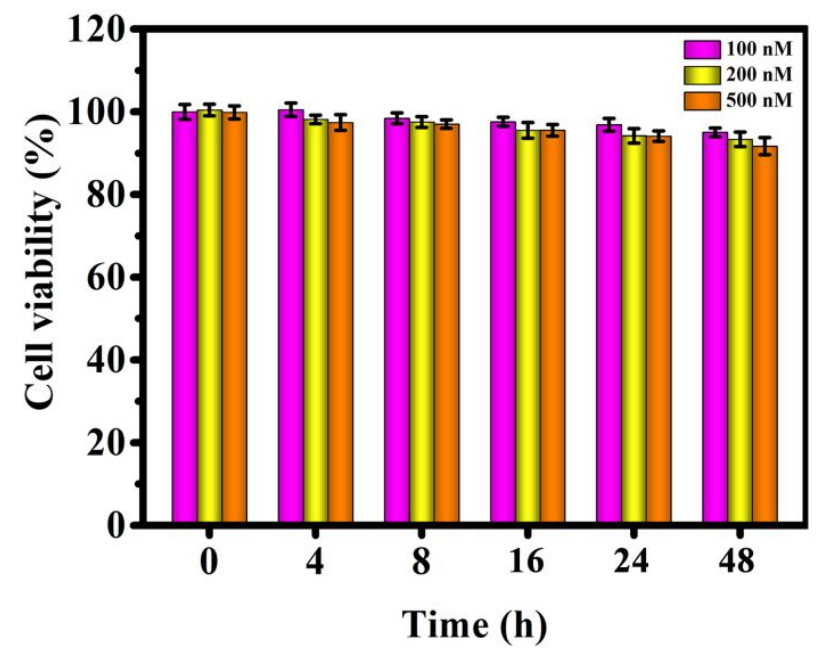

Figure S11. The cytotoxicity of DZNT with varying concentrations $(100,200,500$ $\mathrm{nM})$ to HepG2 cells at $0-48 \mathrm{~h}$. 


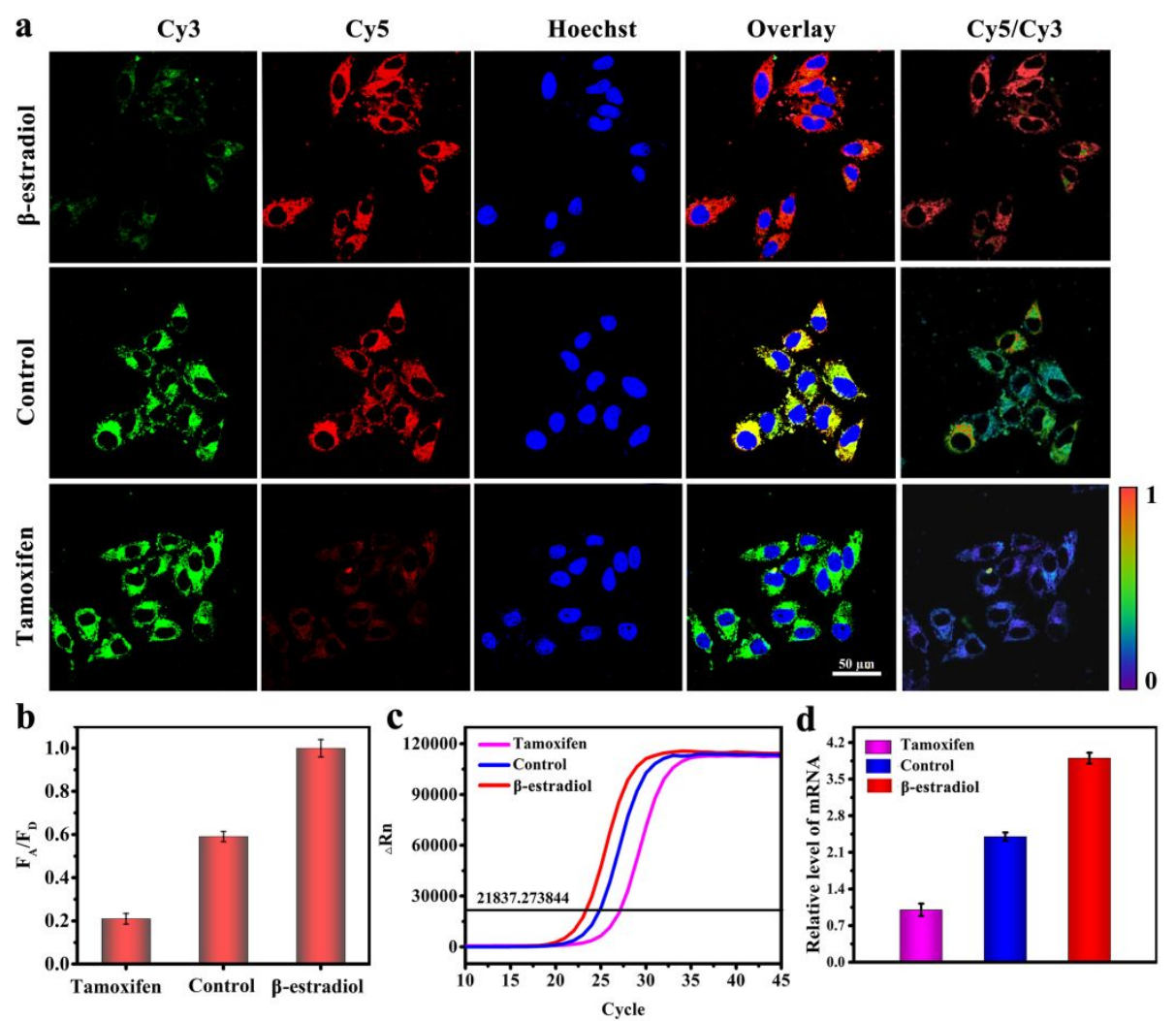

Figure S12. (a) CLSM imaging of different expression levels of TK1 mRNA in HepG2 cells. The top group was treated with $\beta$-estradiol, the middle group was untreated as control, and the bottom group was treated with tamoxifen. (b) The corresponding histogram of the relative fluorescence intensity $\left(\mathrm{F}_{\mathrm{A}} / \mathrm{F}_{\mathrm{D}}\right)$ in the above condition. qRT-PCR analysis of relative expression level of the TK1 mRNA in HepG2 cells treated with $\beta$-estradiol and tamoxifen. (c) Real-time fluorescence curves analysis. The black line indicates the threshold, and the number on the line indicates the threshold value. (d) The TK1 mRNA relative expression levels in the above condition. The error bar is the standard deviation of three repeated tests. 


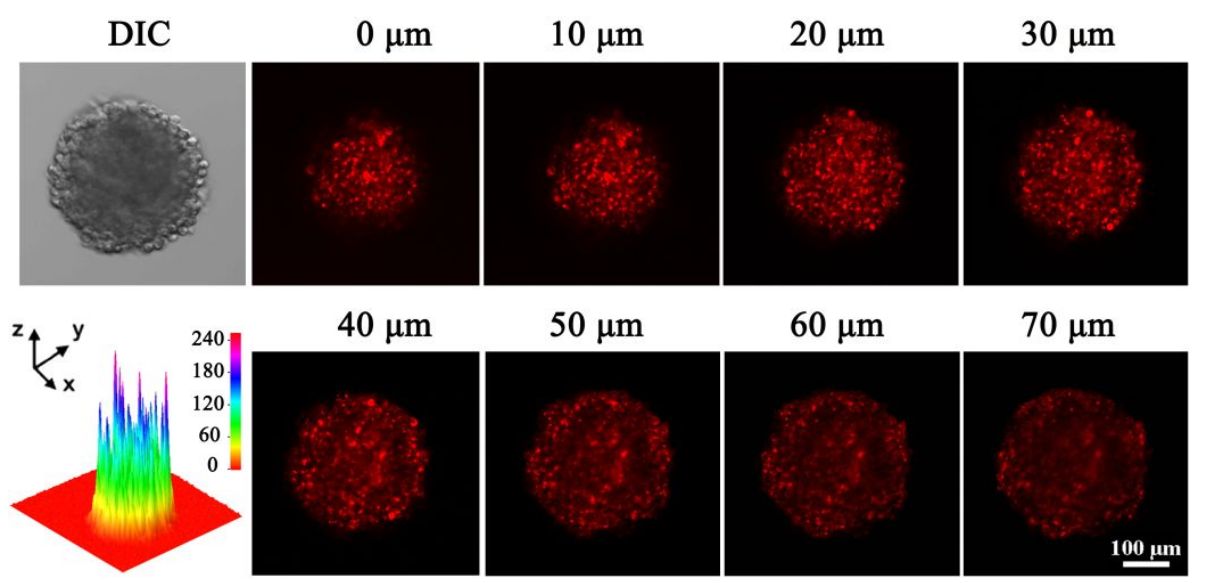

Figure S13. The penetration of DZNT in MCTSs by Z-axis scanning of CLSM. The fluorescence signal was collected at different levels from the top to the middle of the spheroids. Lower left corner: Interactive 3D surface plot of max intensity projection of the Cy5 channel in CLSM. The MCTSs and Cy5-labeled DZNT were incubated at $37^{\circ} \mathrm{C}$ for $5 \mathrm{~h}$, and the penetration and distribution of DZNT were observed by Z-axis scanning of CLSM. The Z-axis scans at different depths of DZNT distribution showed high fluorescence signals. These findings indicated that DZNT could penetrate to the edge of the MCTSs and spread to the center. 


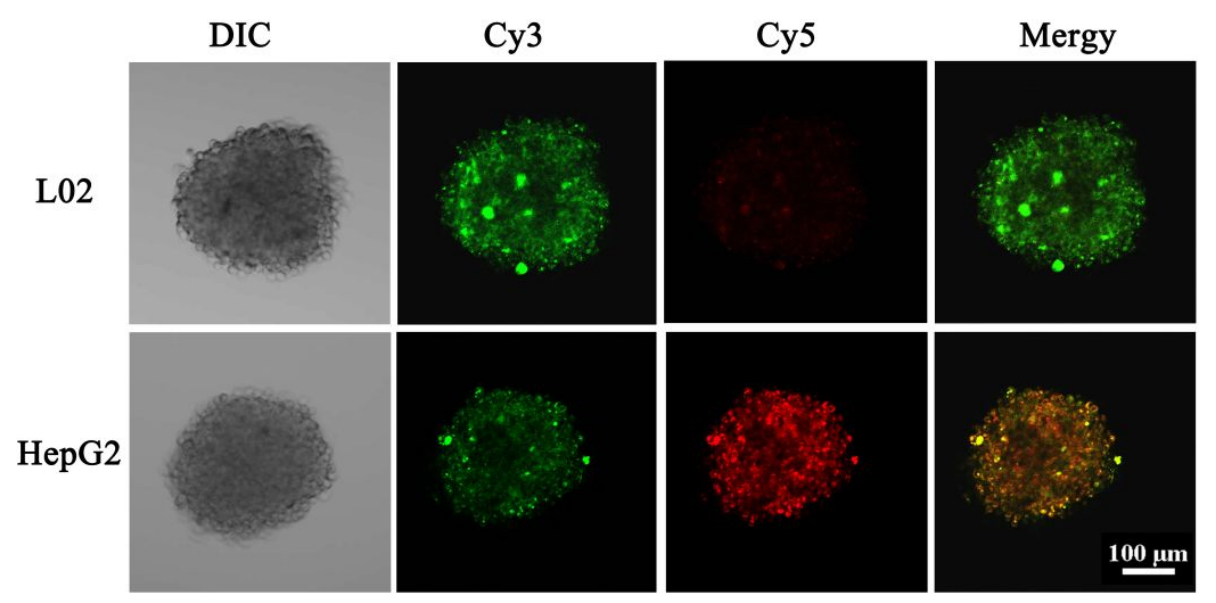

Figure S14. 3D imaging of TK1 mRNA by DZNT in the different MCTSs. The fluorescence signal was collected from the middle section of MCTSs. 


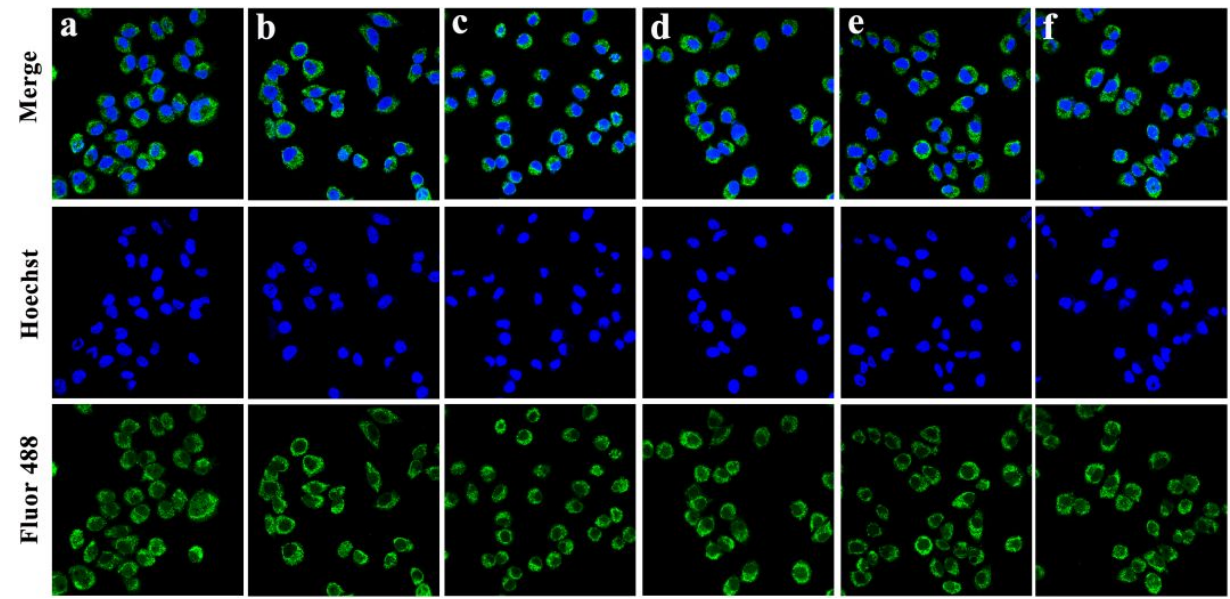

Figure S15. Immunofluorescence analysis with antibodies against survivin protein in the L02 cells after incubation with control (a), ssDNAzyme@ $\mathrm{Mn}^{2+}(\mathrm{b})$, control DZNT@Mn ${ }^{2+}(\mathrm{c})$, control target DZNT@Mn+ ${ }^{2+}(\mathrm{d}), \mathrm{DZNT}(\mathrm{e})$ and DZNT@Mn+ ${ }^{2+}$ (f). 


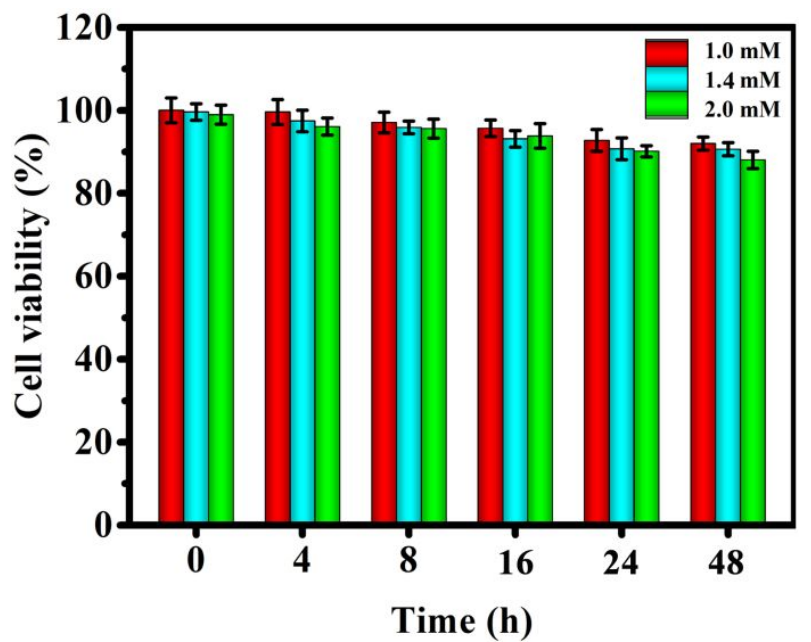

Figure S16. The cytotoxicity of $\mathrm{Mn}^{2+}$ with varying concentrations (1.0, 1.4, $\left.2.0 \mathrm{mM}\right)$ to HepG2 cells at $0-48 \mathrm{~h}$. 


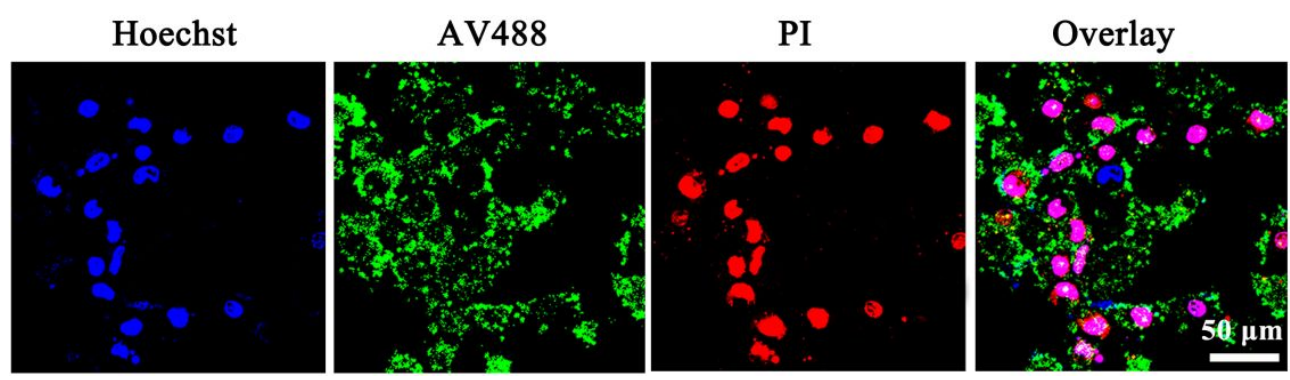

Figure S17. The CLSM imaging of MCF-7 cells treated with DZNT@Mn²+ 

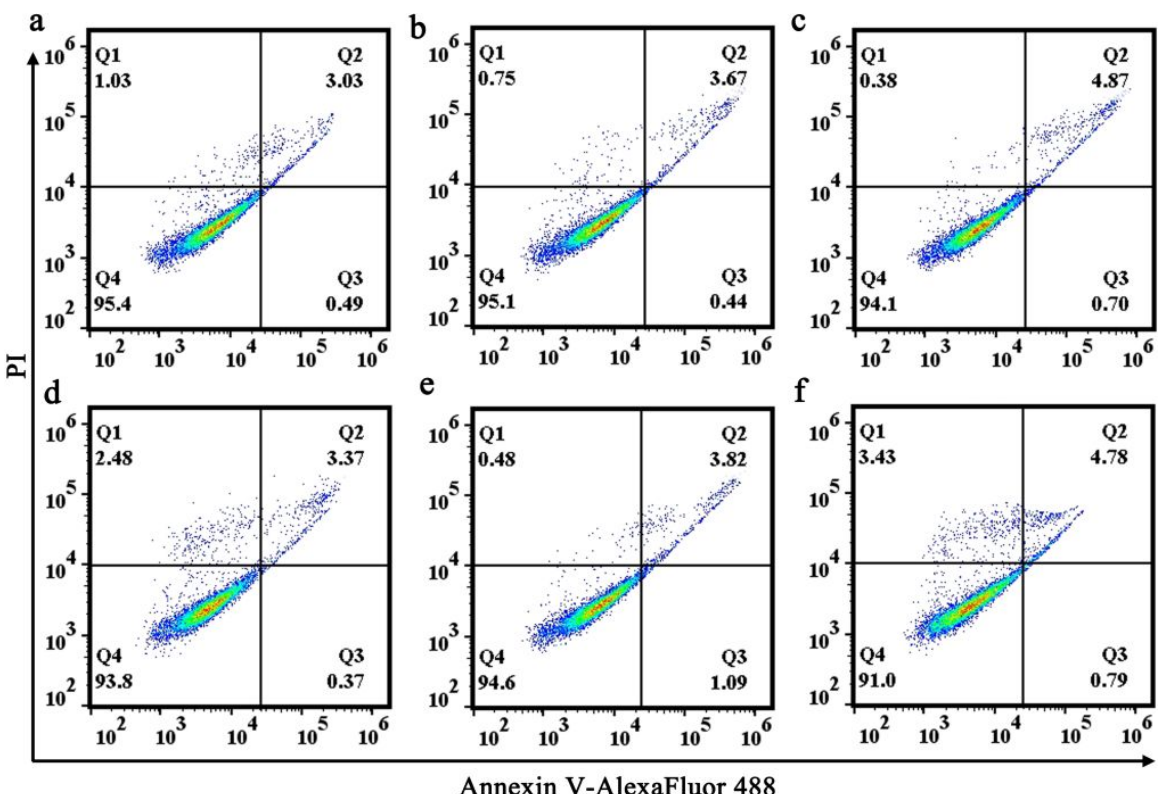

Figure S18. Flow cytometry analysis of L02 cell apoptosis after incubation with control (a), ssDNAzyme@Mn ${ }^{2+}$ (b), control DZNT@ $\mathrm{Mn}^{2+}$ (c), control target DZNT@Mn ${ }^{2+}(\mathrm{d}), \mathrm{DZNT}(\mathrm{e})$ and DZNT@ $\mathrm{Mn}^{2+}(\mathrm{f})$. 


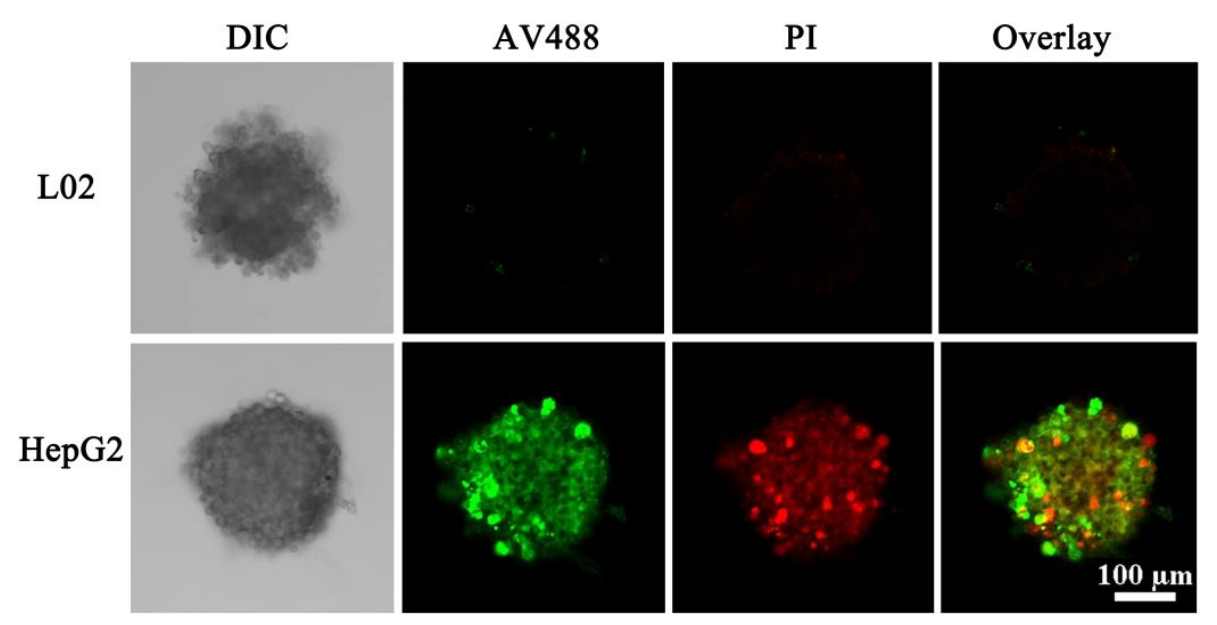

Figure S19. The gene silencing capability of DZNT in MCTSs by Z-axis scanning of CLSM. The fluorescence signal was collected from the middle section of MCTSs. 


\section{REFERENCES}

1. Zhou, F.; Fu, T.; Huang, Q.; Kuai, H.; Mo, L.; Liu, H.; Wang, Q.; Peng, Y.; Han, D.; Zhao, Z.; Fang, X.; Tan, W. Hypoxia-Activated PEGylated Conditional Aptamer/Antibody for Cancer Imaging with Improved Specificity. J. Am. Chem. Soc. 2019, 141, 18421-18427. 